\title{
RECARGA DE AQUÍFERO ALUVIAL SOB USO AGRÍCOLA
}

\author{
RECHARGE IN ALLUVIAL AQUIFER UNDER AGRICULTURAL USE
}

Cleber Gomes de Albuquerque ${ }^{1}$; Suzana Maria Gico Lima Montenegro ${ }^{2 ;}$ Abelardo Antônio de Assunção Montenegro ${ }^{3}$; Robertson Valério de Paiva Fontes Júnior ${ }^{4}$

Artigo recebido em: 07/07/2014 e aceito para publicação em: 04/02/2015

DOI: http://dx.doi.org/10.14295/ras.v29i1.27931

\begin{abstract}
The core in the exploitation of groundwater is its renewal, which is not usually performed in the same proportion of the abstraction. This may result in an exploration of parts of the permanent reserves of the aquifer, with the risk of severe depletion, when the abstraction is not properly monitored. This study aims to estimate the groundwater recharge in the rural area of Pesqueira (PE) from 2002 to 2011. Alluvial aquifers are strategic for communal farming in the Brazilian semiarid. The methodology used was the water balance of Thornthwaite \& Mather and variation of the water level. The first considers climatological and pedological elements for the analysis of the aquifer recharge, while the second method directly analyzes the change in the groundwater level in relation to the storage coefficient of water in the soil. It was found that all the years of the study period showed a deficit of moisture in the soil, in the "late dry period". Results were similar for both methods, being both effective in estimating aquifer recharge in the region.
\end{abstract}

Keywords: Water budget. Irrigated agriculture. Semiarid.

Resumo: O cerne na explotação das águas subterrâneas está na renovação deste recurso, que não se faz na mesma proporção da extração. Isso pode resultar em uma exploração de partes das reservas permanentes do aquífero, com riscos de exaustão, quando a captação não é devidamente monitorada. Este estudo visa a determinação da recarga do aquífero freático na zona Rural do Município de Pesqueira (PE) de 2002 a 2011. Os aquíferos aluviais são estratégicos na região semiárida do Nordeste Brasileiro para agricultura familiar. As metodologias utilizadas foram a do balanço hídrico de Thornthwaite \& Mather e a de variação do nível de água. O primeiro considera elementos climatológicos e de solos para a análise do aquífero, enquanto o segundo método analisa diretamente a variação no nível freático em relação ao coeficiente de armazenamento de água no solo. Verificou-se que todos os anos do período em estudo apresentaram déficit de umidade no solo, no período seco final. Observou-se a similaridade nos resultados dos métodos apresentados, sendo ambos apropriados na estimativa da recarga na região.

Palavras-chave: Balanço hídrico. Agricultura irrigada. Semiárido.

\section{INTRODUÇÃO}

A água subterrânea é reconhecida como reserva estratégica e tem apresentado uso crescente nas últimas décadas. Para o semiárido brasileiro, os aquíferos aluviais são estratégicos para a agricultura familiar, em particular durante os períodos de estiagem. A recarga de aquíferos é comumente definida como a introdução natural ou artificial de água para as camadas do subsolo, aumentando a quantidade de água subterrânea disponível. A variabilidade temporal e espacial da recarga é uma das questões mais importantes dentro das pesquisas hidrológicas, devido a sua importância para a gestão dos recursos hídricos subterrâneos (RABELO \& WENDLAND, 2009; DRIPPS \& BRADBURY, 2010).

A possibilidade da água subterrânea ser extraída varia espacialmente, dependendo das condições de precipitação e das propriedades dos aquíferos. Em geral, a água subterrânea pode ser extraída durante o ano inteiro desde que o seu reabastecimento (recarga) seja adequado e que a mesma encontre-se protegida da poluição (SOUZA, 2009). Gómez et al. (2010) afirmam que o conhecimento da recarga das águas subterrâneas é necessário na resolução de

\footnotetext{
Mestre em Engenharia Civil-UFPE(cleber.albuquerque@outlook.com)

Universidade Federal de Pernambuco - Departamento de Engenharia Civil Grupo de Recursos

Hídricos(suzanam@ufpe.br)

UFRPE (abelardo.montenegro@yahoo.com.br)

4 Mestre em Engenharia Agrícola UFRPE (rr_fontes@ hotmail.com)
} 
questões relacionadas à qualidade das águas, ecologia e bem-estar humano e ambiental, além de modelagem de fluxo subterrâneo e transporte de contaminantes.

O cerne na exploração desse tipo de recurso está na renovação das águas retiradas, ou recarga do aquífero, que não se faz na mesma proporção da extração, sobretudo na região semiárida do Brasil. Isso pode resultar em uma exploração de partes das reservas permanentes do aquífero, com riscos de exaustão, quando a captação não é devidamente controlada. No semiárido do Estado de Pernambuco, as áreas aluvionares são as principais fontes de água subterrânea, em geral de boa qualidade, visto que nas formações cristalinas os poços captam águas salobras, que são usadas apenas para dessedentação de animais ou dessalinizadas para o abastecimento humano. Em tais vales aluviais os solos são em geral férteis, e a principal atividade econômica desenvolvida é a agricultura irrigada (GOMES, 2009). Na região semiárida do Nordeste Brasileiro, os aquíferos aluviais são usualmente explotados para abastecimento de populações difusas e para irrigação em agricultura familiar ou de pequena escala.

Burte et al. (2011) citam a utilização de aquíferos aluviais como uma alternativa adequada para o desenvolvimento do meio rural no Nordeste brasileiro. Devido às suas características, as águas de aquíferos aluviais podem ser utilizadas para irrigação, sendo recomendável um manejo integrado de seu uso, minimizando o risco de salinização e sodificação dos solos e perdas por evaporação.

Muitos métodos de estimativa de recarga têm sido desenvolvidos. Montenegro \& Ragab (2010) aplicaram modelo DiCaSM, Fontes Júnior (2012) aplicou o modelo BALSEQ_MOD e Monteiro (2003) utilizando o Visual Modflow para estimar a recarga subterrânea no mesmo vale aluvial adotado no presente estudo.

O método da variação do nível utiliza informações potenciométricas como indicadores da recarga efetiva. Baseia-se na premissa de que o aumento do nível de água é resultado da recarga à zona saturada do aquífero (BARRETO et al., 2009). O método de Thornthwaite \& Mather (1955) estima o balanço hídrico em ambientes agrícolas, permitindo estimara recarga através do cálculo das entradas (precipitação) e saídas (escoamento superficial e evapotranspiração) da água ao longo do tempo no perfil do solo (MALDANER, 2010).

$\mathrm{O}$ vale aluvial onde está inserida a Fazenda Nossa Senhora do Rosário é um sistema típico da região semiárida do Nordeste Brasileiro onde se explota água subterrânea para abastecimento de populações difusas e para irrigação em agricultura familiar ou de pequena escala. Diversas pesquisas têm sido desenvolvidas nesse vale aluvial, como o trabalho de Fontes Junior (2012), que avaliou o comportamento hidrológico da região sob efeito de recarga e a variabilidade temporal e espacial da salinidade. Complementarmente, Andrade et al. (2012) estudaram a variabilidade espaço-temporal da condutividade elétrica da água subterrânea explotada no vale aluvial.

O presente trabalho teve como objetivo estimar a recarga em um aquífero aluvial intensamente monitorado no semiárido do Estado de Pernambuco, utilizando os métodos do balanço hídrico de Thornthwaite \& Mather (1955) e da variação do nível d'água no período de janeiro de 2002 à dezembro de 2011.

\section{MATERIAL E MÉTODOS}

Este estudo foi desenvolvido no município de Pesqueira (Figura 1), que está situado na mesorregião Agreste e na Microrregião Vale do Ipanema, no Estado de Pernambuco. A área limita-se a norte com Estado da Paraíba e Poção, a sul com os municípios de Venturosa e Alagoinha, a leste com Sanharó, Capoeira, São Bento do Una e Belo Jardim, e a oeste com Arcoverde e Pedra. A sede do município está situada a uma altitude de aproximada de 654 metros e distando $213,7 \mathrm{~km}$ da cidade do Recife (IBGE, 2011). 


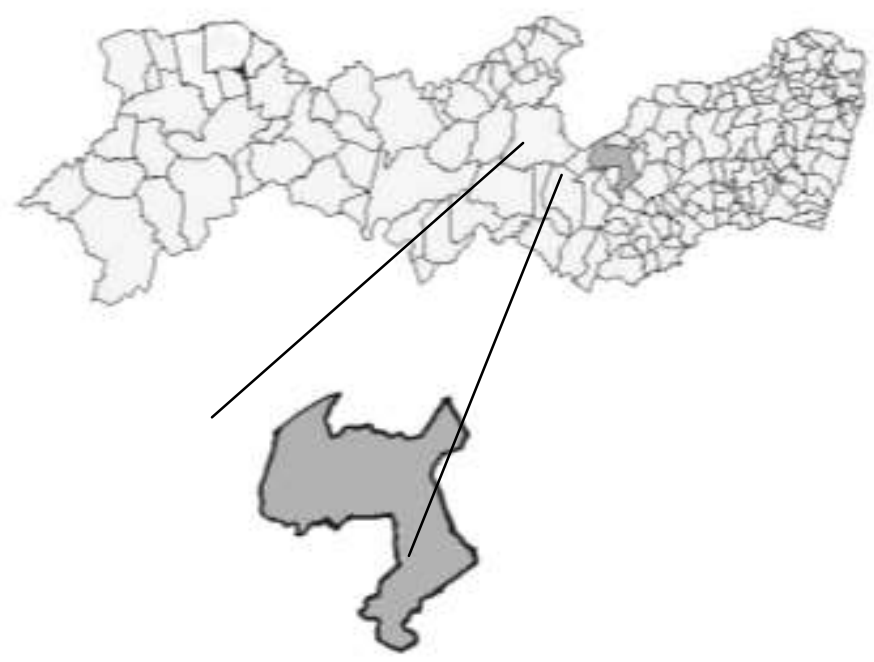

Figura 1- Localização do município de Pesqueira no Estado de Pernambuco

A área de estudo está localizada no vale aluvial na Fazenda Nossa Senhora do Rosário e na região conhecida como Flexeira Velha, ambas na bacia do Alto Ipanema, situada a 26,3 $\mathrm{km}$ da sede do município de Pesqueira, com coordenadas geográficas de $08^{\circ} 10^{\prime} \mathrm{S}$ e $35^{\circ} 11^{\prime}$ $\mathrm{W}$, de latitude e longitude, respectivamente, e $650 \mathrm{~m}$ de altitude. O clima do local é classificado, segundo Köeppen, como BShw' semiárido quente, caatinga hiperxerófila, com temperatura média anual em torno de $27^{\circ} \mathrm{C}$, umidade relativa média anual do ar de $73 \%$ e velocidade média do vento de $2,5 \mathrm{~m} \mathrm{~s}^{-1}$ (MONTENEGRO \& MONTENEGRO, 2006). A região da Fazenda Nossa Senhora do Rosário possui uma malha de poços e piezômetros que foram cadastrados e georreferenciados. Cada um possui cerca de 5 metros de profundidade e diâmetros de 100 $\mathrm{mm}$, protegidos com tela e com filtro em cascalho. Na região mais a jusante da bacia, existem aproximadamente 67 piezômetros, 4 poços comunitários e 29 poços particulares (ANDRADE et al., 2012). As contribuições de recarga subterrânea no vale (região no centro leste da bacia do Alto Ipanema, com Neossolo Flúvico e Regolítico (Figura 2) provêm lateralmente das regiões de Sucavão, Flexeira Velha, Coité e Caraíbas e superficialmente com os riachos Mimoso, Ipaneminha e Jatobá.

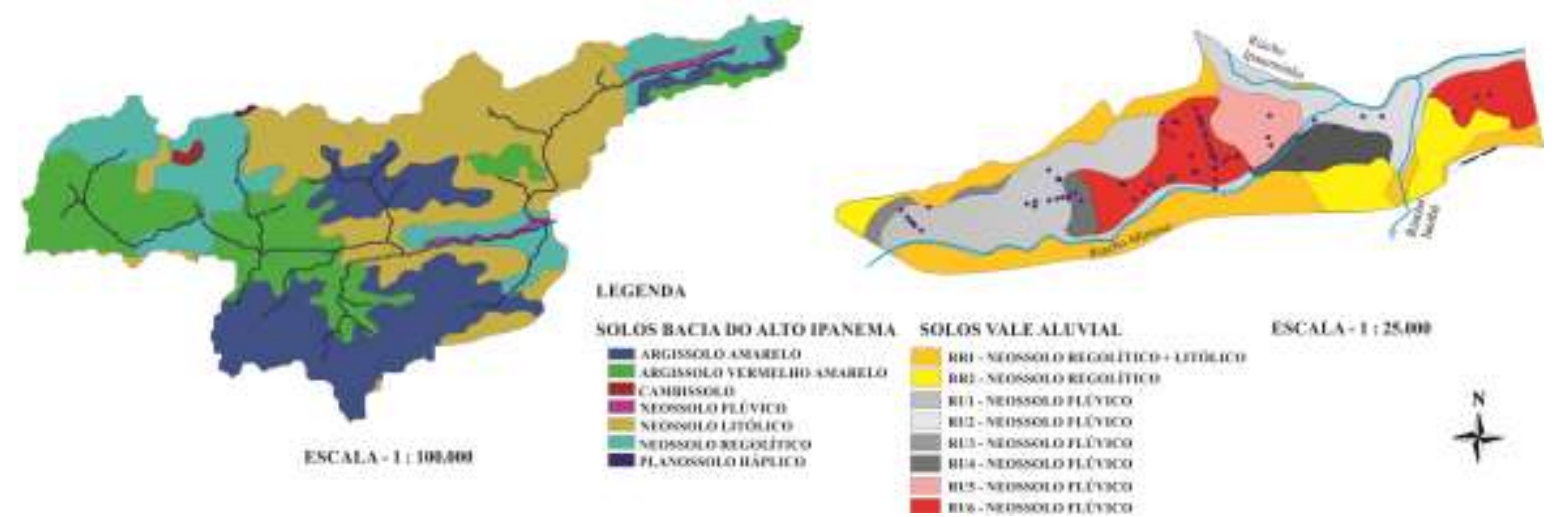

Figura 2 - Mapa de solos da bacia do Alto Ipanema (adaptado de Montenegro e Ragab (2010)) 

A região em análise se caracteriza pela má distribuição das chuvas no tempo e no espaço, apresentando um período de estiagem, convencionado como seco final, que ocorre de setembro a dezembro e seco inicial, em janeiro e fevereiro, além do período chuvoso, de março a junho (SANTOS et al., 2011). A avaliação da recarga seguiu duas metodologias: a de variação de nível d'água e do balanço hídrico. O primeiro método foi adotado por Andrade et al. (2012) na fazenda Nossa Senhora do Rosário. A outra metodologia empregada foi a de Thornthwaite \& Mather (1955), que através do cálculo do balanço hídrico, estima a recarga. $\mathrm{O}$ período considerado neste trabalho foi de Janeiro de 2002 a Dezembro de 2011. Para este período, a precipitação média anual foi de 778,2 $\mathrm{mm}$.

\section{Método de variação do nível d'água}

Para a metodologia de variação do nível d'água, foram adotados dados mensais do nível dos 67 piezômetros em conjunto com dados mensais de pluviometria da região. Assumiu-se o coeficiente de armazenamento $(S)$ de 0,10 para a área, obtido com os testes de bombeamento na ocasião da construção dos poços. Pode-se avaliar assim a recarga total $\mathrm{R}_{\text {total }}$ (Eq. 1) como:

$$
R_{\text {total }}=\frac{\Delta h}{S}+R_{\text {lateral }}
$$

Onde $\Delta \mathrm{h}$ representa a variação do nível do lençol entre dois meses consecutivos, em milímetros e $\mathrm{S}$, o coeficiente de armazenamento do aquífero e $\mathrm{R}_{\text {lateral }}$ a recarga lateral, derivadas das encostas da zona de influência ao norte e sul da área em estudo, como parte indispensável da contribuição da recarga total. A recarga lateral foi adotada com êxito por Monteiro (2003), assumindo que a contribuição lateral introduzse no aquífero ao longo da interface entre o embasamento aflorante e o vale. $\mathrm{O}$ critério validado adequadamente pelo autor assumiu que $10 \%$ do total de recarga das bacias circunvizinhas serve de volume de recarga ao aquífero.

\section{Método de Thornthwaite \& Mather (1955)}

Para a metodologia de Thornthwaite \& Mather, foi determinado o regime hídrico do local sem necessidade de medidas diretas das condições do solo. Na sua elaboração foi necessário definir o armazenamento máximo do solo (CAD - Capacidade de Água Disponível) e de se ter a medida da precipitação total, e também a estimativa da evapotranspiração potencial em cada período. De posse destas informações, o balanço hídrico climático permite deduzir a evapotranspiração real, a deficiência ou excedente hídrico e o total de água retida no solo.

Esse método estima a recarga direta através do cálculo das entradas e saídas de água na bacia hidrográfica ao longo do tempo no perfil do solo, sendo definido na Eq. 2 como:

$$
P+E S C=E T R+A R M+R
$$

Sendo:

$P$ - precipitação (mm);

$E S C$ - fluxos superficiais para dentro da área de estudo (mm);

ETR - evapotranspiração real (mm);

$A R M$ - variação no armazenamento de água na zona não-saturada $(\mathrm{mm})$;

$R$ - recarga (mm).

De acordo com o método de Thorntwaite \& Mather (1955), para uma sequencia de " $n$ " meses com estiagem após a estação chuvosa, o armazenamento (ARMn) ao longo desses meses é calculado pela Eq. 3:

$$
A R M n=C A D \times \exp \left(\frac{N e g \text { acum }}{C A D}\right)=C A D \times \exp \left(\frac{\Sigma(P-E T P) n}{C A D}\right)
$$

Sendo:

$A R M n$ - armazenamento no mês " $\mathrm{n}$ "

$C A D$ - armazenamento máximo no solo. Segundo Thorntwaite \& Mather (1955), CAD varia de $25 \mathrm{~mm}$ a $400 \mathrm{~mm}$.

$P$ - precipitação média mensal no mês "n”(mm)
ETP - evapotranspiração de referência no mês " $n$ " calculado por Penman-Monteith da FAO (mm)

Neg acum - somatório anual dos negativos acumulados até o mês " $n$ ". 
No caso de meses com (P-ETP) $<0$ utiliza-se a Eq 4.:

$A R M_{n}=A R M_{n-1} \times \exp \left(\frac{(P-E T P) n}{C A D}\right)$

Havendo um ou mais meses com (PETP) $>0$, mas com valores insuficientes para elevar o ARM até o valor do CAD, segue-se a rotina normal com a Eq. 5:

$$
A R M_{n}=A R M_{n-1}+(P-E T P)_{n}
$$

Segundo o método, é necessário escolher um mês no fim do período de estiagem e antes do início do período chuvoso. Inicialmente utiliza-se a Eq. 6.:

$$
A R M=\frac{M}{1-\exp \left(\frac{N}{C A D}\right)}
$$

Sendo

ARM - armazenamento no mês $M$ - somatório de (P-ETP) positivos em $\mathrm{mm}$ $N$ - somatório de (P-ETP) negativos em mm

A Figura 3 mostra o fluxograma com os procedimentos para cálculo dos valores de armazenamento, evapotranspiração real, déficit e excedente hídrico em milímetros.

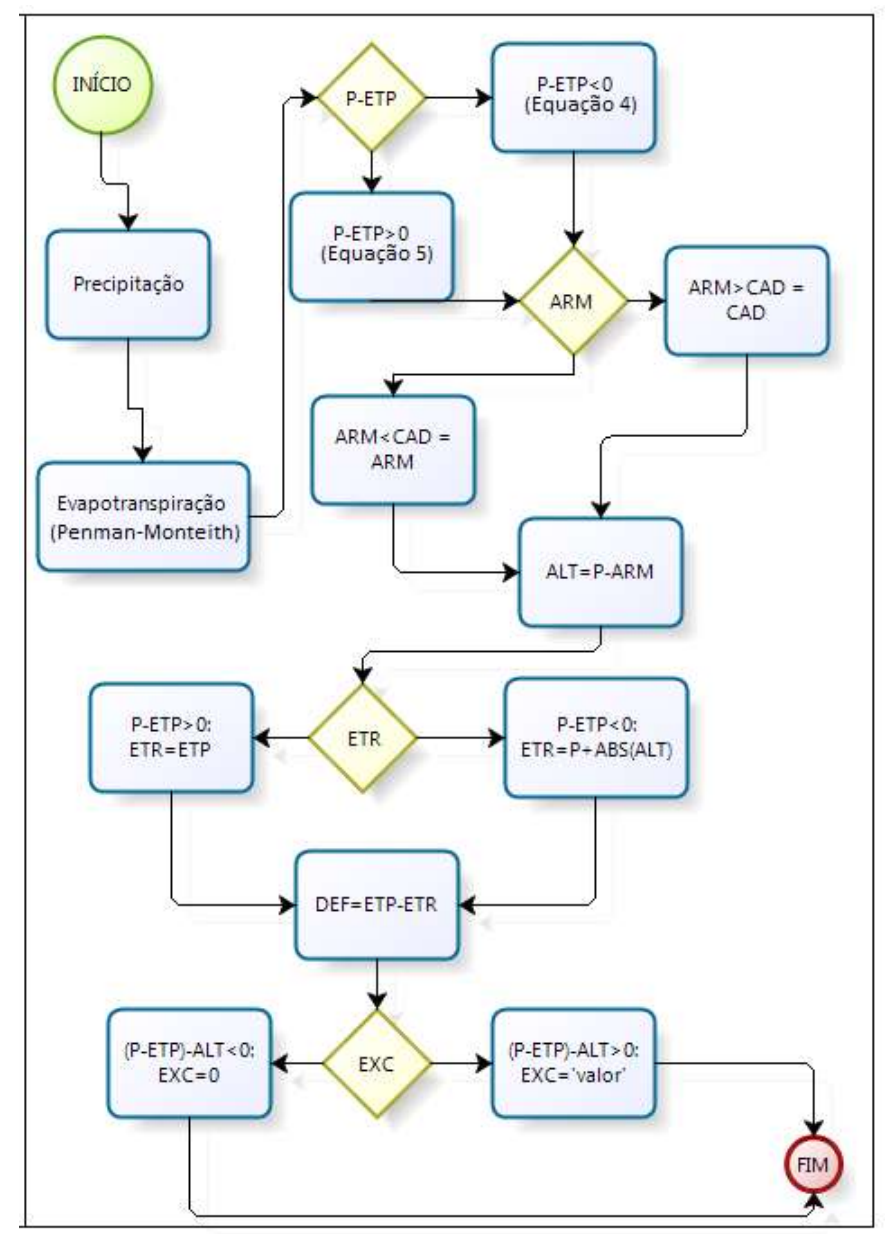

Figura 3 - Fluxograma com o método de Thornthwaite \& Mather (1955) 
Fontes Junior (2012) realizou levantamento do uso e ocupação do solo no vale da Fazenda Nossa Senhora do Rosário através de visitas in loco. A Tabela 1 apresenta os intervalos de valores de $C A D$ e respectivos valores médios para cada tipo de vegetação existente no vale aluvial e a Figura 4 o mapa com as áreas de uso e ocupação do solo, atualizado em 2012. Estes valores foram obtidos por Pereira et al.(2002), que indicam valores entre 25 e 50 $\mathrm{mm}$ para hortaliças, entre 75 e $100 \mathrm{~mm}$ para culturas anuais, entre 100 e $125 \mathrm{~mm}$ para culturas perenes e entre 150 e $300 \mathrm{~mm}$ para espécies florestais. Blackburn et al. (2002) calcularam para a área em estudo o valor da variação de armazenamento de água no solo da ordem de $110 \mathrm{~mm}(C A D)$ através de lâminas acumuladas de irrigação. Thornthwaite \& Mather (1955) supuseram um $C A D$ de 100 mm, bem próximo do valor calculado por Blackburn et al. (2002), embora os valores possam variar de $25 \mathrm{~mm}$ a $400 \mathrm{~mm}$, a depender da capacidade de campo, ponto de murcha permanente e peso específico aparente do solo.

Tabela 1 - Tipos de uso e ocupação para o Vale Aluvial

\begin{tabular}{|c|c|c|c|c|}
\hline Nome & Código & Descrição & $C A D$ & $\begin{array}{c}C A D \\
\text { médio }\end{array}$ \\
\hline Mata & MT & Mata arbustiva caatinga & $25-50$ & 37,5 \\
\hline Mata/Capim & MT_CM & Mata arbustiva de capim & $25-50$ & 37,5 \\
\hline Capim & $\mathrm{CM}$ & Área com capim & $25-50$ & 37,5 \\
\hline Mata/hortícula (cenoura) & MT_HRC & Área de mata com hortaliça & $25-50$ & 37,5 \\
\hline Capim/Pastagem & CM_PS & Área com capim e pastagem & $25-50$ & 37,5 \\
\hline Hortícula (pimentão) & HRP & Área de cultivo de pimentão & $25-50$ & 37,5 \\
\hline Urbano & UR & Vila dos agricultores & $25-50$ & 37,5 \\
\hline Cenoura & HRC & Cultivo de cenoura & $25-50$ & 37,5 \\
\hline Mata/Urbano & MT_UR & Área de mata próxima à vila & $25-100$ & 62,5 \\
\hline Pimentão/Frutífera & HRP_FR & $\begin{array}{l}\text { Cultivo de pimentão com árvo- } \\
\text { res }\end{array}$ & $25-125$ & 75 \\
\hline Mata/Frutífera & MT_FR & Mata arbustiva com árvores & $25-125$ & 75 \\
\hline Capim/Frutífera & CM_FR & Área com capim e frutíferas & $25-125$ & 75 \\
\hline Capim/Cana & CM_CA & $\begin{array}{c}\text { Área com capim e cana de } \\
\text { açúcar }\end{array}$ & $25-125$ & 75 \\
\hline Mamona/Mandioca & MA_T & $\begin{array}{l}\text { Plantações de mamo- } \\
\text { na/mandioca }\end{array}$ & $75-100$ & 87,5 \\
\hline Sem cobertura & $\mathrm{SC}$ & Solo sem cobertura & 110 & 110 \\
\hline Frutífera & FR & Árvores frutíferas & $100-125$ & 112,5 \\
\hline
\end{tabular}

Fonte: Adaptado de Fontes Júnior et al. (2012) 


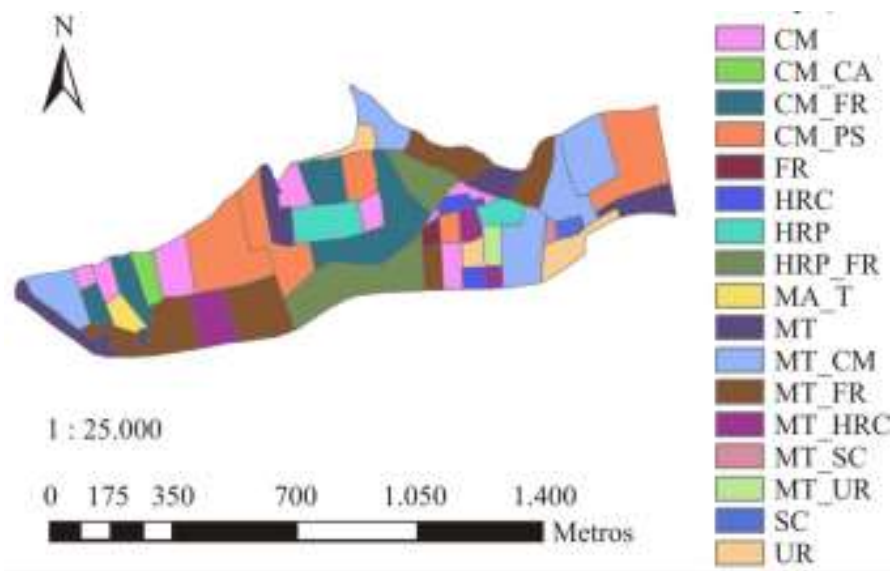

Figura 4 - Mapa típico de uso e ocupação do solo da Fazenda Nossa Senhora do Rosário

A evapotranspiração potencial (ETP) foi calculada utilizando-se o método de Penman-Monteith da FAO, através de dados climatológicos registrados na estação total da Fazenda Nossa Senhora do Rosário (FONTES JUNIOR, 2012). Os valores de ETP mensal variaram de $482,48 \mathrm{~mm}$ à $40,70 \mathrm{~mm}$, sendo o menor valor registrado em dezembro de 2010 e o maior em setembro de 2011.

O escoamento superficial é estimado aplicando-se o coeficiente de escoamento superficial $\left(C^{\prime}\right)$ à precipitação mensal (Maldaner, 2010):

$$
E S C=C^{\prime} \cdot P
$$

Onde

$$
C^{\prime}=\alpha \cdot C
$$

$C$ é o coeficiente que determina o volume de precipitação que escorrerá em superfície, em função do tipo do solo. $O$ coeficiente $\alpha$ é determinado em função da declividade e da estação do ano, seca ou úmida, mostrado na Tabela 2.

Tabela 2- Valores de $C$ e $\alpha$ em função do tipo do solo, declividade e estação do ano

\section{Coeficiente $\alpha$}

Tipo de solo $\quad$ Declividade $(\%) \quad$ Estação seca $\quad$ Estação úmida

\begin{tabular}{rlll} 
Arenoso & 0 a 2 & 0,17 & 0,34 \\
$\mathbf{C = 0 , 3 0}$ & 2 a 7 & 0,34 & 0,50 \\
Argiloso & 0 a 2 & 0,33 & 0,43 \\
$\mathbf{C = 0 , 4 0}$ & 2 a 7 & 0,45 & 0,55 \\
\hline
\end{tabular}

Fonte: Maldaner (2010)

A topografia do vale é uniforme com declividade em torno de $0,3 \%$ e, segundo Montenegro et al. (2010), os tipos de solo no vale são predominantemente arenosos, podendo-se adotar o coeficiente $\alpha$ com valor de 0,17 na estação seca e 0,34 na estação úmida, além do coeficiente do volume de precipitação $C$ ser igual a 0,30. Santos et al. (2011) enfatizam a má distribuição das chuvas na região, assim como acontece na região semiárida do nordeste, que apresenta o período de estiagem de setembro a fevereiro e o chuvoso de março a agosto.

\section{RESULTADOS E DISCUSSÃO}

\section{Recarga pelo método de variação do nível d'água}

Segundo a metodologia de variação do nível d'água, foram obtidos valores de recarga, relacionadas com o período chuvoso e período 
seco inicial, sendo raro aparecimento de recarga durante o período seco final.

Neste método, o ano 2002 registrou eventos de recarga no período seco inicial e durante praticamente todo período chuvoso. No ano 2003, ano atípico seco observado também no método de Thornthwaite \& Mather (1955), teve um único evento de recarga no mês de fevereiro, sendo todo o resto do período de saída de água do lençol freático. Em 2004, houve a maior recarga do lençol $(27,47 \%$ do total). A partir de 2005, observa-se uma tendência dos eventos de recarga acontecerem principalmente no período chuvoso. Este fato ocorreu até o ano 2008, representando $40 \%$ do da recarga no período em análise.
O ano de 2009 foi o de maior recarga desde o ano 2004, com 12,35\% do total. Em 2010, houve recuperação do lençol no período seco final e inicial, porém os maiores eventos de recarga ocorreram em seu período chuvoso. A não continuidade dos eventos de recarga no decorrer deste período é justificado pela variação da chuva de um mês para outro alternando entre uma baixa e uma alta precipitação, não suficiente para promover acréscimo do nível potenciométrico. Isto também justifica o ano de 2011, que registrou o maior evento chuvoso em um único mês do período de chuvas, em maio. Os outros meses de chuva não foram suficientes para manter a recarga ou evitar o déficit hídrico.

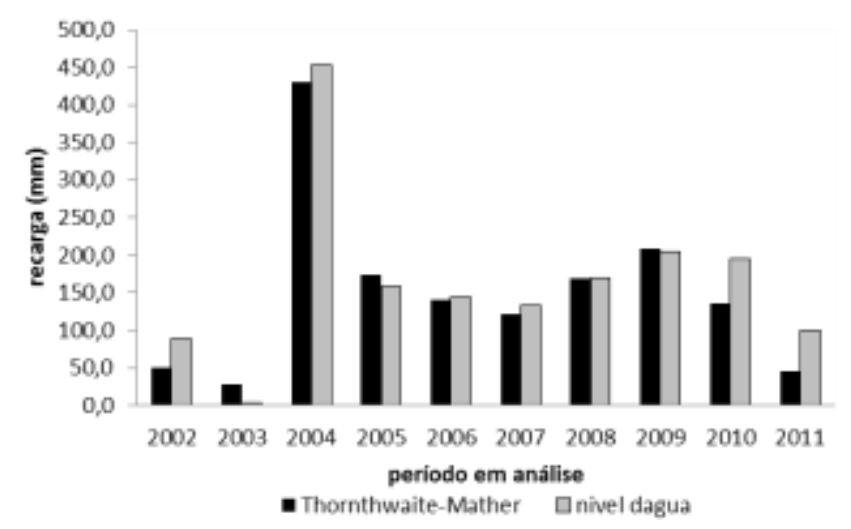

Figura 5 - Diferença entre os valores totais de recarga nos anos analisados

Andrade (2010) utilizou o método de variação do nível d'água e estimou a recarga nos anos 2008 e 2009 na Fazenda Nossa Senhora do Rosário, tendo observado que as chuvas de valores insignificantes não são capazes de contribuir para a recarga do lençol freático, fato observado de 2002 a 2011 neste trabalho. Ape- nas precipitações de volumes médios mensais superiores a $100 \mathrm{~mm}$ durante o ano hidrológico geram recarga no aquífero, assim como observado por Andrade (2010) para a Fazenda Nossa Senhora do Rosário - PE. A figura 6 mostra a variação da recarga em todo período analisado, pelo método de variação do nível d'água.

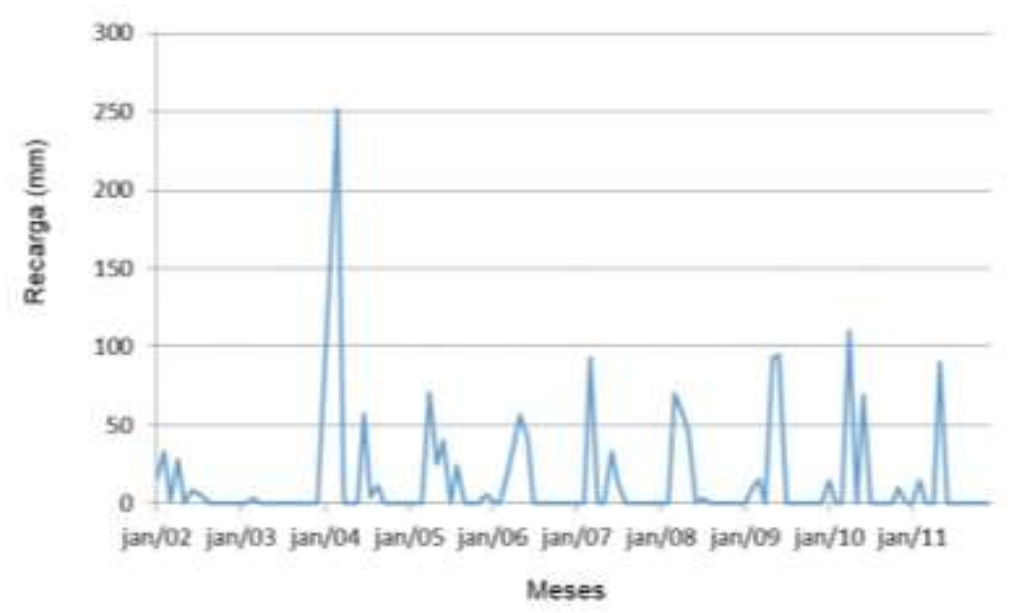

Figura 6 - recarga pelo método do nível d'água no período em análise (2002 a 2011). 


\section{Recarga pelo método de Thornthwaite \& Mather}

De acordo com o balanço hídrico, pelo método de Thornthwaite \& Mather (1955), o total precipitado no período estudado serviu para diminuir o déficit hídrico e a perda d'água, promovendo a recarga principalmente no período chuvoso local, como esperado. Observou-se que, para acontecer a recarga, foram necessários eventos chuvosos em que o acumulado mensal atingisse $100 \mathrm{~mm}$. Este valor foi observado como a quantidade mínima de precipitação para que houvesse acréscimo no armazenamento de água no solo capaz de promover uma recarga efetiva no aluvião, assim como verificado por Andrade et al. (2012).

$\mathrm{O}$ ano de 2002 registrou um baixo excedente hídrico de $1,15 \mathrm{~mm}$ no mês de junho (período chuvoso). A recarga aconteceu durante o período chuvoso e seco inicial, decrescendo durante o período seco final. No período seco final de 2002, a pluviometria também diminuiu, chegando ao ano de 2003, onde ocorreu um ano atípico seco. Observou-se que toda precipitação deste ano foi praticamente perdida por evapotranspiração e a recarga total foi de apenas $27,7 \mathrm{~mm}$. Esse foi o ano com o maior registro de déficit hídrico e perda de água na área em estudo. O ano de 2004 teve uma considerável recuperação no armazenamento de água no solo nos meses de janeiro e junho, quando ocorreram valores muito acima da capacidade de água disponível calculada por Blackburn et al. (2002). Isto acarretou na diminuição no déficit hídrico deste ano, resultando na recarga do lençol freático no início do periodo seco inicial e da metade pro fim do período chuvoso. No ano 2005, ocorreu recarga apenas no período chuvoso, entre os meses de março e junho. Em 2006, assim com o ano anterior, houve acréscimos no armazenamento de água no solo no período de maior precipitação. $\mathrm{O}$ ano 2007 apresentou um comportamento de recuperação do lençol freático diferente, que ocorreu desde o período seco inicial, em janeiro, até o mês de junho.

Comportamento semelhante ocorreu no ano 2008, que concentrou a recarga até o mês de julho. Em 2009, o valor do armazenamento foi um dos maiores do período em estudo, embora os eventos de recarga tenham se concentrado no período seco inicial. Em 2010, a recuperação do armazenamento também se apresentou em sua maior parte, fora do período chuvoso e se estendeu até dezembro. $\mathrm{O}$ ano de 2011, acompanhando a tendência do ano anterior, registrou eventos de recarga desde o início até maio. Outros acréscimos aconteceram durante o período seco final, de menor amplitude. Maldaner (2010) também utilizou o método de Thornthwaite \& Mather (1955) e como esperado, nos meses com grande volumes de chuvas, a recarga foi maior, exatamente como na região da Fazenda Nossa Senhora do Rosário, mesmo com as configurações dos parâmetros locais e precipitação relativamente inferior do que a região de Jales e Urânia - SP.

O balanço hídrico climático também foi utilizado por Soares \& Velásquez (2013), na bacia do do rio Riachão, no norte de Minas Gerais. Os autores afirmam a vantagem da metodologia de Thornthwaite \& Mather, que depende da consistência dos dados coletados, a fim de evitar um somatório de erros ao longo das etapas. Assim como neste trabalho, a evapotranspiração representou um importante fator de perda d'água, limitando a quantidade de água disponível para a recarga pela contribuição da precipitação e escoamento superficial. A figura 7 mostra a variação da recarga em todo período analisado, pelo método de Thornthaite \& Mather. 


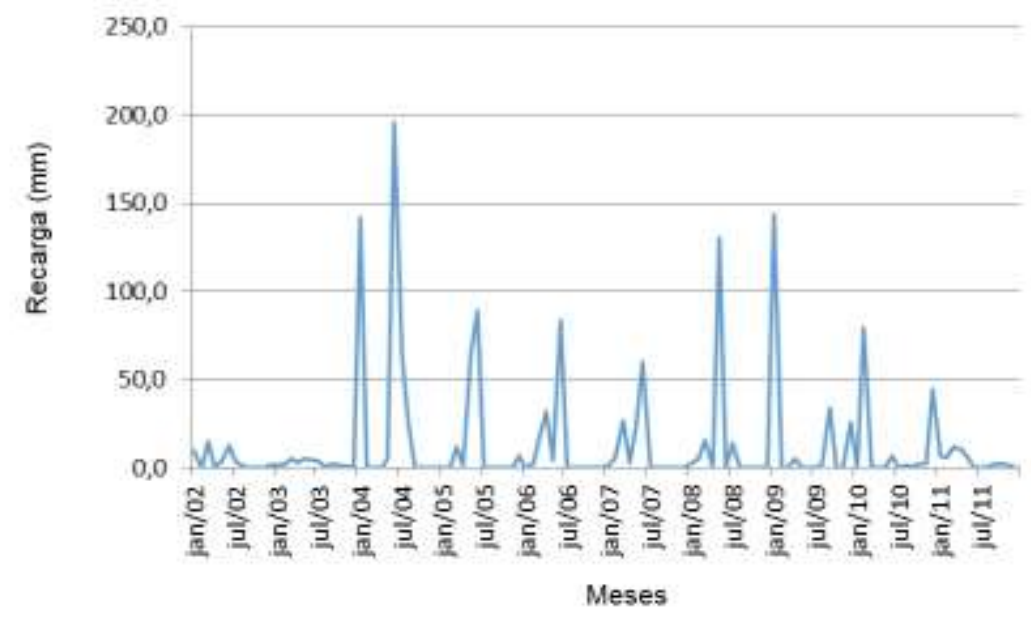

Figura 7 - Recarga pelo método Thorntwaite \& Mater no período em análise (2002 a 2011).

\section{Comparação entre os métodos de estimativa de recarga}

O total acumulado para os anos estudados da recarga, estimado pelo método Thornthaite \& Mather (1955) foi $1501,5 \mathrm{~mm}$ em média de $12,5 \mathrm{~mm}$ por mês, enquanto o método de variação do nível d'água foi 1652,4 $\mathrm{mm}$ com média de $13,8 \mathrm{~mm}$ por mês. A Figura 5 mostra a comparação entre os valores de recarga no período em análise.

A metodologia de variação do nível d'água apresenta bons resultados de estimativa, por levar em consideração o acréscimo no nível do lençol freático de acordo com a chuva ocorrida na região e o decréscimo no nível durante o período de estiagem. Por outro lado, o método de Thornthwaite \& Mather estima a recarga baseada em elementos climatológicos e de solo, explicitando diretamente a recarga e a saída de água do lençol freático. Segundo os métodos utilizados, para que aconteça a recarga, é necessária uma precipitação mensal média em igual ou superior a $100 \mathrm{~mm}$, como observado anteriormente por Andrade (2010).

A Figura 8 apresenta a aproximação entre os dois métodos, que possui uma correlação de Pearson $r=0,97$. Esta afinidade pode ser explicada pela adição da recarga lateral no método de variação do nível d'água e o escoamento de entrada na bacia e coeficiente de armazenamento no método de Thornthaite \& Mather. Estas complementações são necessárias para suprir as considerações de cada método, onde a diferença dos valores de recarga corresponde a apenas 1,9\% da precipitação total.

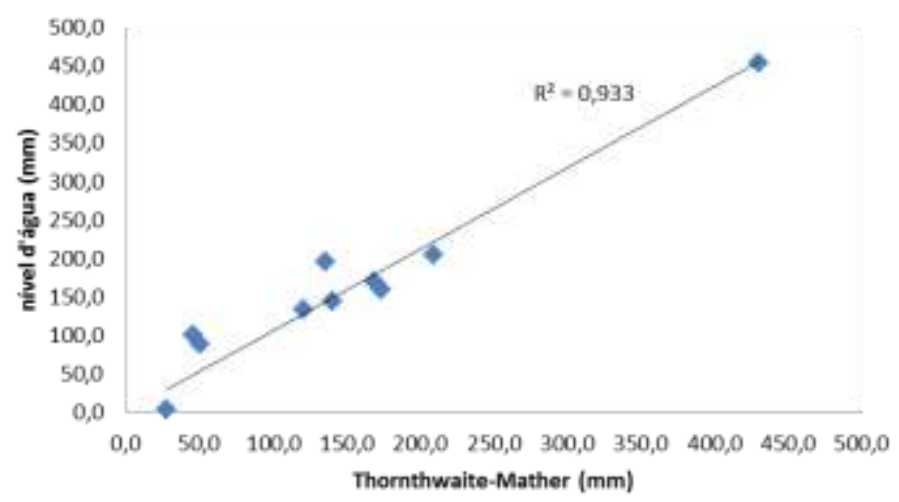

Figura 8 - Correlação entre os valores de recarga pelo método da variação do nível d' água e método de Thornhwait 

A estimativa da recarga pelo método de variação do nível d'água quantifica de forma mais direta a dinâmica potenciométrica por considerar a elevação e rebaixamento do nível freático, diferente do método de Thornthwaite \& Mather (1955), que estima toda a variação da recarga considerando fatores climáticos e de solo da bacia hidrográfica. Como esperado, a maior parte do abastecimento do lençol freático é resultante precipitação direta.

Utilizando o método do balanço hídrico de Thornthwaite \& Mather, foram identificados eventos de recarga entre janeiro de 2002 a dezembro de 2011. Todos os anos apresentaram déficit de umidade no solo em algum momento do ano, principalmente durante o período seco final. Da precipitação total ocorrida nos anos em estudo (1501,5 mm), apenas 1,84\% ocorreu no ano 2003, que foi o ano atípico seco. Porém no ano seguinte, ocorreu a maior precipitação anual do período, com $28,63 \%$ do total. O segundo ano mais chuvoso foi 2009 , com $13,92 \%$ do total. Os anos 2005 a 2008 e 2010 apresentaram valores em torno de $10 \%$ do total. Depois de 2003, os anos de 2002 e 2011 apresentaram os menores valores e recarga anual, em torno de $5 \%$.

Utilizando-se o método de variação do nível d'água, foram observados relevantes eventos de recarga entre janeiro de 2002 e dezembro de 2011. A recarga total do período estudado foi de $1652,4 \mathrm{~mm}$. Como esperado, o ano 2003 apresentou a menor recarga, assim como no método anterior representando neste caso apenas $0,21 \%$ do total. Consequentemente, 2004 apresentou $27,47 \%$ do total de recarga, seguido dos anos 2009, com 12,34\% e 2010, com $11,79 \%$. Os anos com os menores lâminas de recarga, depois de 2003 foram 2002 (5,33\%) e 2011 (6,08\%). Todos os outros anos apresentaram eventos de recarga aproximadamente entre 8 e $10 \%$ do total.

\section{CONCLUSÕES}

O monitoramento dos níveis piezométricos das águas subterrâneas tem sido uma ferramenta importante para a verificação da resposta do sistema aos eventos de precipitação.

\section{REFERÊNCIAS}

ANDRADE, T. DA S. Variabilidade espacial e temporal de atributos hidrológicos para gerenciamento de recursos hídricos em aluvião no semiárido sob
As principais origens de recarga na região de Flexeira Velha e Nossa Senhora do Rosário são a água da chuva que cai diretamente na área e devido a contribuições regionais. Esta localidade está livre de outras contribuições observadas nos centros urbanos, como fugas da rede de água. Devido à inexistência de sistema de tratamento de esgoto, existe a contribuição deste para recarga. Porém, em termos de quantidade, é um valor insignificante e menor que o da chuva direta. Pode-se considerar a irrigação também uma fonte de contribuição para a recarga, embora esta mesma água seja retirada de poços cacimbões da localidade. Pelos motivos apresentados, recomenda-se que, em estudos futuros, para uma melhor estimativa da recarga na região e/ou para comparação com os resultados aqui apresentados, sejam utilizados métodos como o de relação entre águas superficiais e aquífero, como realizado por Juárez et al., (2012) em Doñana, Espanha. Há possibilidade de se comparar a recarga no local através do método WTF dos anos seguintes, desde que a coleta de dados aconteça em intervalos mais curtos ou que a instalação do equipamento de medição, como o Levelogger. Faz-se necessário um acompanhamento dos eventos de recarga em períodos onde ocorram eventos de chuva com maior volume, com intuito de se verificar melhor a relação entre as ocorrências de precipitação e excedente hídrico nessa região da bacia do rio Ipanema, importante para as famílias que sobrevivem da criação de animais e da agricultura irrigada. É essencial o envolvimento de órgãos públicos para auxiliar as comunidades locais em períodos como o que é apresentado neste trabalho, onde o déficit hídrico compromete a economia da região.

\section{AGRADECIMENTOS}

À CAPES (Coordenação de Aperfeiçoamento de Pessoal de Nível Superior) e à FACEPE (FUNDAÇÃO DE AMPARO À PESQUISA DO ESTADO DE PERNAMBUCO) pela concessão da bolsa de Mestrado, à FINEP pelo financiamento ao projeto de pesquisa, ao CNPq por bolsas de PQ e à UFPE e UFRPE pelo apoio institucional. 
ANDRADE, T. DA S.; MONTENEGRO, S. M. G. L.; MONTENEGRO, A. A. A.; RODRIGUES, D. F. B. Variabilidade espaço-temporal da condutividade elétrica da água subterrânea na região semiárida de Pernambuco. Revista Brasileira de Engenharia Agrícola e Ambiental, v. 16, n. 5, p. 496-504, 2012.

BARRETO, C. E. A. G.; WENDLAND, E.; MARCUZZO, F. F. N. Estimativa da evapotranspiração a partir de variação de nível estático de aquífero. Revista Engenharia Agrícola, v.29, n. 1, p.52-61, 2009.

BLACKBURN, D. M.; MONTENEGRO, A. A. A; MONTENEGRO, S. M. G. L. Recarga de aquífero aluvial a partir de agricultura irrigada e suas implicações na qualidade da água subterrânea em Pesqueira- PE. In XII Congresso Brasileiro de Águas Subterrâneas, 2002, Florianópolis: Águas Subterrâneas/ABAS, 2002, v. 1. p. 1-9.

BURTE, J.; COUDRAIN, A.; MARLET, S. Uso das águas de pequenos aquíferos aluviais para irrigação nas regiões semiáridas. Revista Ciência Agronômica, v. 42, n. 3, p. 1-9, 2011.

DRIPPS, W. R.; BRADBURY, K. R. The spatial and temporal variability of groundwater recharge in a forested basin in Northern Wisconsin. Hydrological Processes, v.24, p.383-392, 2010.

FONTES JÚNIOR, R. V. P. Estudo da estabilidade e variabilidade temporal do nível freático e salinidade visando à análise de recarga. Recife, Pernambuco, Brasil, 2012. 89p. Dissertação (Mestrado em Engenharia Agrícola). Universidade Federal Rural de Pernambuco.

GOMES, D. F.; FRISCHKORN, H. Aspectos da hidrodinâmica do aquífero aluvial do rio Jaguaribe, em Limoeiro do Norte - Ceará. Águas Subterrâneas, v. 23, n. 1, p. 45-68, 2009.

GÓMEZ, A. A.; RODRÍGUEZ, L. B.; VIVES, L. S. The Guarani Aquifer System: estimation of recharge along the Uruguay-Brazil border. Hydrogeology Journal, n. 18, p.1667-1684, 2010.

IBGE. Instituto Brasileiro de Geografia e Estatística. $<$ http://www.ibge.gov.br/cidadesat/topwindow.htm? $1>10$ Out. 2011.

MALDANER, C. H. Recarga de aquífero em área urbana: estudo de caso de Urânia (SP). São Paulo, Brasil, 2010. 101p. Dissertação (Mestrado em Recursos Minerais e Hidrogeologia). Universidade de São Paulo.
MONTEIRO, A. L. N. Avaliação do Potencial de pequenos aluviões com irrigação através de modelagem computacional. Recife, Pernambuco, 2003. 88p. Dissertação (Mestrado em Ciências do Solo). Universidade Federal Rural de Pernambuco.

MONTENEGRO, A. A. A.; COSTA NETTO, M.L.; MONTENEGRO, S. M. G. L.; SILVA, E. F. F.; FONTES JUNIOR, R. V. P. Avaliação da salinidade de neossolo usando-se dispositivo de indução eletromagnética. Revista Brasileira de engenharia agrícola e ambiental, v. 14, n. 6, 2010.

MONTENEGRO, A. A. A. E MONTENEGRO, S. M. G. L. Variabilidade espacial de classes de textura, salinidade e condutividade hidráulica de solos em planície aluvial. Revista Brasileira de Engenharia Agrícola e Ambiental, v.10, n.1, p. 30-37, 2006.

MONTENEGRO, A. A. A.; RAGAB, R. Hydrological response of a Brazilian semiarid catchment to different land use and climate change scenarios: modelling study. Hydrological Processes, v. 24, p. 2705-2723, 2010.

PEREIRA, A. R.; ANGELOCCI, L. R.; SENTELHAS, P. C. Agrometeorologia: fundamentos e aplicações práticas. Guaíba: Editora agropecuária. 2002.

RABELO, J. L.; WENDLAND, E. Assessment of groundwater recharge and water fluxes of the Guarani Aquifer System, Brazil. Hydrogeology Journal, v. 17, p. 1733-1748, 2009.

SANTOS, T. E. M.; MONTENEGRO, A. A. A.; SILVA, D. D. Umidade do solo no semiárido Pernambucano usando-se reflectometria no domínio do tempo (TDR), Revista Brasileira de Engenharia Agrícola e Ambiental, v.15, p.670-679, 2011.

SOARES, L. C; VELÁSQUEZ, L. M. N. Estimativa da recarga aquífera na bacia do rio Riachão, Norte de Minas Gerais. Revista Águas Subterrâneas v. 27, n. 2 p.104-120, 2013.

SOUZA, N. A. Vulnerabilidade à poluição das águas subterrâneas - um estudo do aquífero Bauru na zona urbana de Araguari, MG. Uberlândia, Minas Gerais, Brasil, 2009. 94p. Dissertação (Mestrado em Engenharia Civil). Universidade Federal de Uberlândia.

THORNTHWAITE, C.W.; MATHER, J.R. The water balance. Publications in Climatology, v. 8, n.1 104 p, 1955. 